\title{
UK Renal Registry 15th Annual Report: Chapter 4 Demography of the UK Paediatric Renal Replacement Therapy Population in 2011
}

\author{
Rishi Pruthi ${ }^{\mathrm{a}}$, Catherine O’Brien ${ }^{\mathrm{b}}$, Anna Casula ${ }^{\mathrm{a}}$, Fiona Braddon ${ }^{\mathrm{a}}$, Malcolm Lewis ${ }^{\mathrm{c}}$, \\ Heather Maxwell ${ }^{d}$, Yincent Tse ${ }^{\mathrm{e}}$, Carol Inward ${ }^{\mathrm{f}}$, Manish D Sinha ${ }^{\mathrm{g}}$ \\ aUK Renal Registry, Bristol, UK; 'birmingham Children's Hospital, Birmingham, UK; 'Manchester Children's Hospital, \\ Manchester, UK; ${ }^{d}$ Royal Hospital for Sick Children (Yorkhill), Glasgow, UK; ${ }^{e}$ Royal Victoria Infirmary, Newcastle, UK; \\ fBristol Royal Hospital for Children, Bristol, UK ${ }^{9}$ Evelina Childrens Hospital, London, UK
}

\section{Key Words}

Aetiology $\cdot$ Children · Demography $\cdot$ End stage renal disease - Established renal failure $\cdot$ Incidence $\cdot$ Prevalence $\cdot$ Ethnicity - Renal replacement therapy · Survival

\begin{abstract}
Aims: To describe the demographics of the paediatric RRT population under the age of 16 years in the UK and to analyse changes in demography with time. Methods: Data were collected from all 13 paediatric renal centres within the UK. A series of cross-sectional and longitudinal analyses were performed to describe the demographics of paediatric RRT patients. Results: A total of 856 children and young people under 18 with ERF were receiving treatment at paediatric nephrology centres in 2011. At the census date, $80.1 \%$ had a functioning transplant, $10.5 \%$ were receiving
\end{abstract}

peritoneal dialysis (PD) and $9.4 \%$ were receiving haemodialysis (HD). In patients aged $<16$ years the prevalence of ERF was 56.8 pmarp and the incidence 8.3 pmarp. Analysis of trends over the last 15 years shows that both incidence and prevalence are increasing. A third of the prevalent patients had one or more reported comorbidities. At transfer to adult services, $86 \%$ of patients had a functioning renal transplant. Pre-emptive transplantation was seen to occur in $31 \%$ of children starting RRT under 16 years, with lower rates seen in girls and ethnic minorities. Survival in childhood amongst children starting RRT was the lowest in those aged less than 2 years. Conclusions: The data provided in this report show increasing trends over 15 years in the incidence and prevalence of established renal failure. This is important for the planning of the provision of care for children needing renal replacement therapy. Further research is required to understand the gender and ethnic differences in pre-emptive transplantation rates and the reduced survival amongst children aged less than 2 years.
Manish D Sinha

UK Renal Registry, Southmead Hospital, Southmead Road, Bristol, BS10 5NB, UK

Email: renalregistry@renalregistry.nhs.uk 


\section{Introduction}

Established renal failure (ERF) requiring renal replacement therapy (RRT) is a rare but significant cause of long term morbidity and mortality during childhood, with specialist care being provided in 13 paediatric nephrology centres in the UK. All centres are equipped to provide peritoneal dialysis and haemodialysis, with ten centres also undertaking kidney transplantation for children. In the United Kingdom (UK), prevalence rates of treated ERF in children aged under 16 have risen steadily over the last 15 years to 59.3 per million age related population (pmarp) in 2010 [1]. Incidence rates for ERF have also shown an increasing trend during this time period rising to 8.1 pmarp in 2010 [1].

The objectives of this report are:

(i) To describe the UK prevalence, incidence, causes of ERF and modality of treatment of children on RRT on 31st December 2011

(ii) To describe trends of the same over the past 15 years, and

(iii) To describe pre-emptive transplantation rates and survival of children on RRT aged $<16$ years old in the UK.

\section{Methods}

Data collection was performed by all 13 paediatric nephrology centres managing children on RRT in the UK in 2011. Most centres submitted data electronically to the UK Renal Registry (UKRR) with only four centres submitting data using paperbased data returns this year. These data items were then manually entered into the current paediatric UKRR database. Southampton was only able to provide a limited electronic dataset due to recent implementation of a bespoke renal IT system.

In this report, patient groups are described as: (i) 'prevalent' group: patients who were receiving RRT on the 31st December 2011; (ii) 'incident' group: patients who started RRT between 1st January and 31st December 2011; and (iii) '5 year' groups: patients who started RRT in the periods of 1997-2001, 20022006 and 2007-2011.

The populations used to calculate the incidence and prevalence rates were obtained from the Office for National Statistics (ONS) [2]. The mid-2011 population estimate produced by the ONS, based on the 2011 Census, was used for calculating the 2011 incident and prevalent group rates; the 2001 Census data was used for the 1997-2001, 2002-2006 and 2007-2011 '5 year' groups.

Infants under the age of 3 months and 'late presenters' (defined as children commencing dialysis within three months following review by a paediatric nephrologist) were excluded from analyses when calculating pre-emptive transplantation rates. For survival analysis, only patients starting RRT between 1st January 1997 and 31st December 2010 were included to ensure a minimum of 1 year follow up at the date of census, 31st December 2011, and were followed up to a maximum age of 16 years.

\section{Statistical analyses}

Statistical analyses were performed using SAS 9.3, with group analyses using Chi-square test and median analyses using KruskalWallis test. A Cox regression model was used in calculating hazard ratios for patient survival, adjusting for gender, age at start of RRT, and RRT modality as a time dependent variable. Survival probabilities were calculated using univariate Kaplan Meier curves.

\section{Results}

\section{Accuracy and completeness of data returns}

Significant efforts to improve the overall accuracy of the entire paediatric dataset by clinical teams, data managers and statisticians have continued this year, resulting in improved accuracy of the database, analyses and conclusions. As for data returns, the procedures for data collection and processing are still evolving but are yielding consistent results, now with near $100 \%$ data completeness achieved by all centres for a range of data items including, gender, ethnicity, treatment modality at start of RRT and age at start of RRT. Data completeness for other core items was better than previous reports and is shown in table 4.1 [1].

The UK paediatric prevalent ERF population in 2011

A total of 856 children and young people under 18 years with ERF were receiving treatment at paediatric nephrology centres in 2011. At the census date, $80.1 \%$ had a functioning kidney transplant, $10.5 \%$ were receiving peritoneal dialysis (PD) and 9.4\% were receiving haemodialysis (HD).

Patients aged 16-18 years may receive their medical care either in a paediatric or in an adult nephrology centre. As data were incomplete for the 16-18 year old adolescent patients they have been excluded from the majority of subsequent analyses (particularly when describing incidence and prevalence rates). This report therefore presents data largely relating to patients less than 16 years of age.

There were 675 children under 16 years of age receiving RRT in the UK in 2011. Table 4.2 shows the number of patients receiving RRT by age group and gender plus rate of RRT pmarp. The prevalence of RRT increased with age and was higher in males across all age groups 
Table 4.1. Data completeness for paediatric prevalent ERF population in 2011

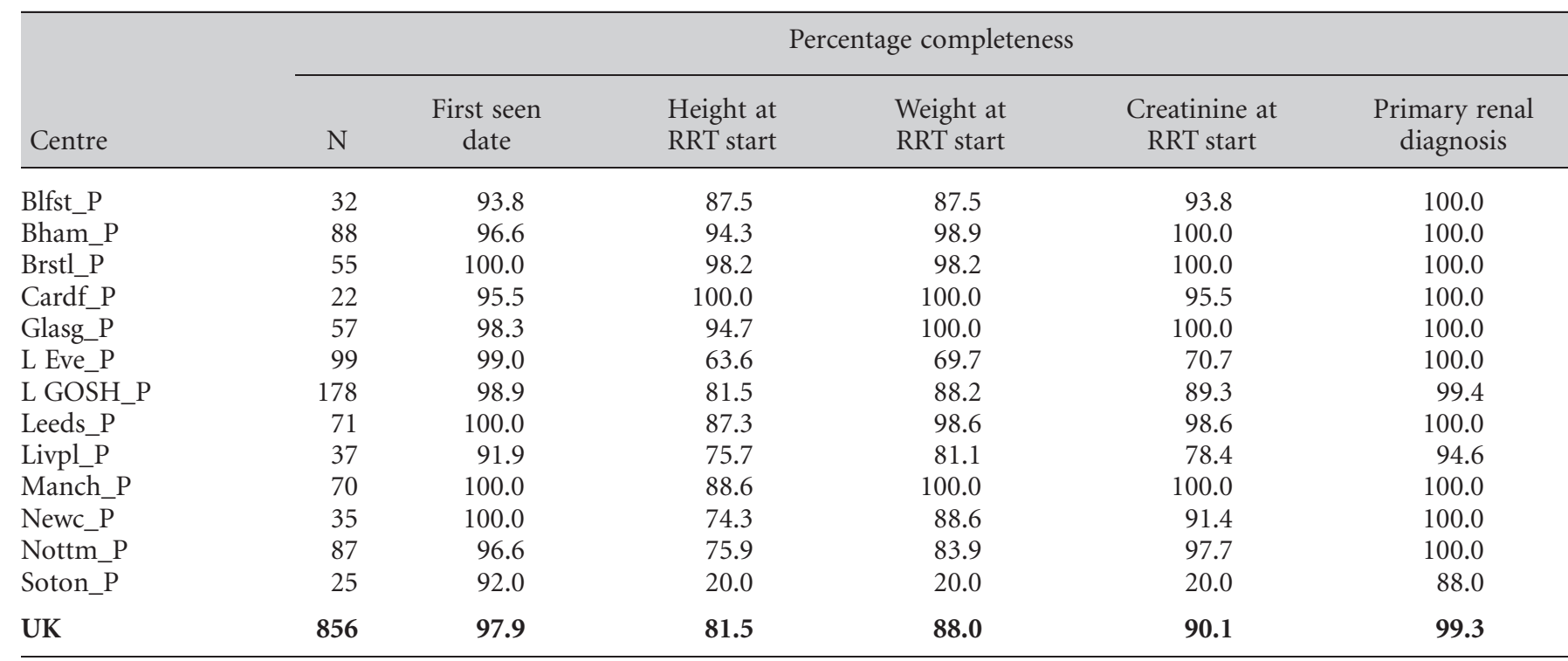

Table 4.2. The UK paediatric prevalent ERF population in 2011, by age group and gender

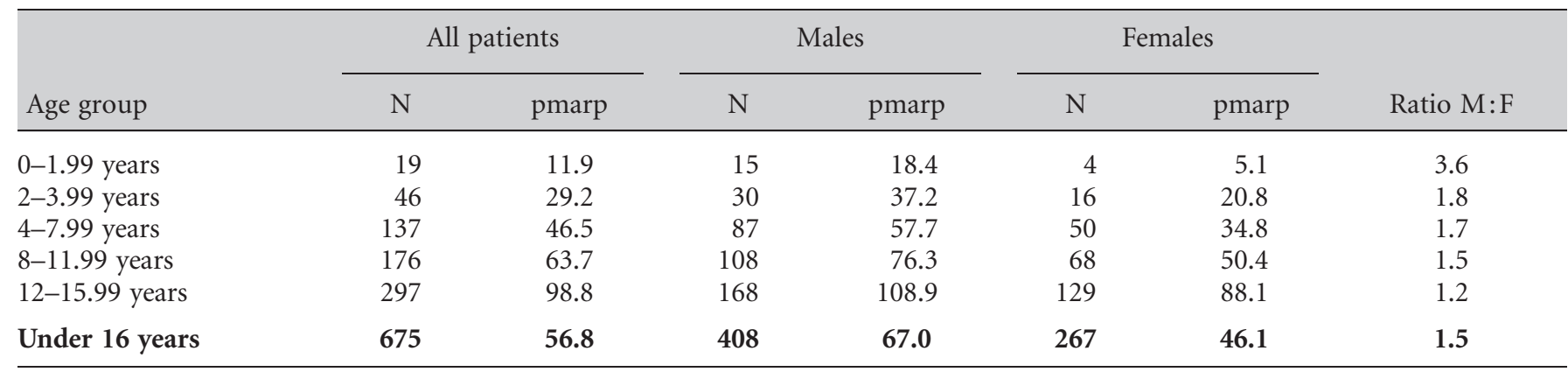

pmarp - per million age related population

with an overall male to female prevalence ratio of 1.5. The reported prevalence rate in under 16 year olds was 56.8 pmarp.

Table 4.3 shows the ethnic origin of current RRT patients and their prevalence rates. Increasing prevalence pmarp was observed with increasing age in all ethnic groups. Children from ethnic minorities displayed higher prevalent rates of RRT when compared with White children, with South Asian children displaying the highest prevalence rates.

Table 4.3. The UK paediatric prevalent ERF population by age and ethnic group in $2011^{\star}$

\begin{tabular}{|c|c|c|c|c|c|c|c|}
\hline \multirow[b]{2}{*}{ Age group } & \multicolumn{2}{|c|}{ White } & \multicolumn{2}{|c|}{ South Asian } & \multicolumn{2}{|c|}{ Black } & \multirow{2}{*}{$\begin{array}{c}\text { Other }^{* *} \\
\mathrm{~N}\end{array}$} \\
\hline & $\mathrm{N}$ & pmarp & $\mathrm{N}$ & pmarp & $\mathrm{N}$ & pmarp & \\
\hline $0-3.99$ years & 48 & 18.6 & 10 & 47.4 & 0 & 0.0 & 7 \\
\hline $4-7.99$ years & 101 & 42.2 & 21 & 107.7 & 6 & 76.9 & 9 \\
\hline $8-11.99$ years & 133 & 52.0 & 24 & 115.1 & 8 & 95.9 & 9 \\
\hline $12-15.99$ years & 221 & 82.0 & 40 & 182.1 & 14 & 159.4 & 21 \\
\hline Under 16 years & 503 & 49.2 & 95 & 113.9 & 28 & 83.9 & 46 \\
\hline
\end{tabular}

pmarp-per million age related population

${ }^{*}$ ethnicity data missing in 3 children who are excluded from this table

** pmarp not expressed for group 'Other', as heterogeneous group 


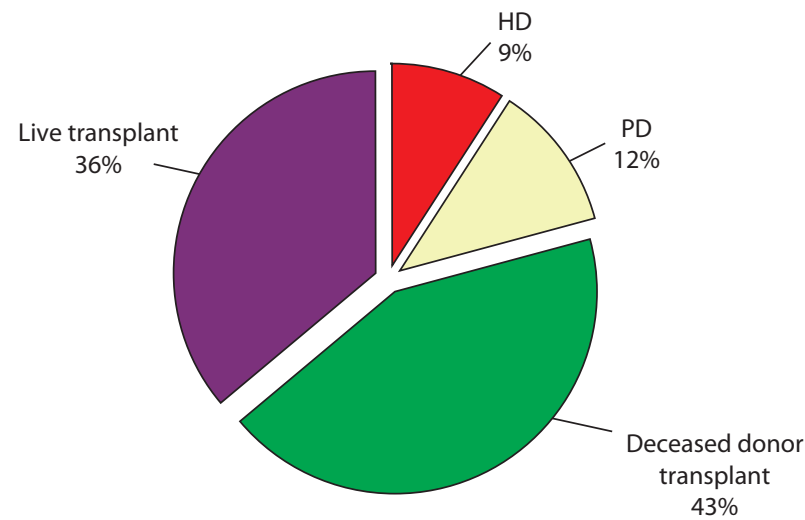

Fig. 4.1. RRT treatment used by prevalent paediatric patients $<16$ years old in 2011

\section{Modality of treatment}

Current treatment modality in the prevalent paediatric population less than 16 years old in 2011 is displayed in figure 4.1 . Of the $79 \%$ with a functioning transplant, $54 \%$ received deceased donor transplantations.

The treatment modality in use at the start of RRT is displayed in figure 4.2. This shows that $48 \%$ of patients were treated with PD at the start of RRT whilst $28 \%$ of patients were treated with HD. Twenty-four percent of children under 16 were reported to have received a pre-emptive transplant.

Further treatment modality analysis by age is shown in table 4.4 which demonstrates that in the under 2 year olds the majority of patients were being treated with PD (63.2\%). This contrasts with older children in the 12 to 15.99 year age group where $85.9 \%$ had a functioning graft and where similar proportions were on $\mathrm{HD}$ and

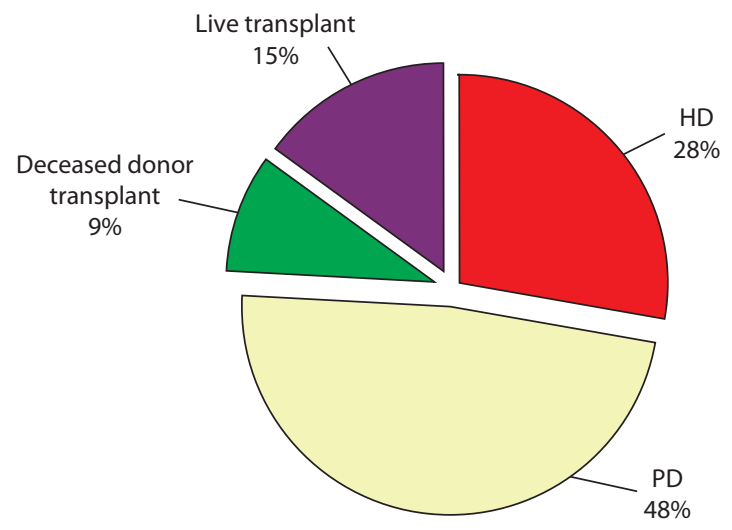

Fig. 4.2. Treatment modality at start of RRT in prevalent paediatric patients under 16 years of age in 2011

PD. Subsequent analysis of RRT modality by gender and ethnicity showed no difference. However as absolute sub-group numbers are small, caution is needed in conducting any comparative analyses.

\section{Cause of ERF}

Table 4.5 and figure 4.3 show the diagnostic categories for the prevalent ERF population under 16 years in 2011. There has been a marked improvement in data completeness in this category over the last few years with missing data falling to only $0.4 \%$ from $2.9 \%$ in the 2010 report [1]. Of the 675 patients, renal dysplasia \pm reflux remained the commonest condition causing ERF $(32.3 \%)$, whilst there were no documented patients with drug nephrotoxicity.

As for associated comorbidities at the onset of RRT, table 4.6 shows that congenital abnormalities were the

Table 4.4. Current treatment modality by age in the prevalent paediatric ERF population in 2011

\begin{tabular}{|c|c|c|c|c|c|c|c|c|}
\hline \multirow[b]{3}{*}{ Age group } & \multicolumn{8}{|c|}{ Current treatment } \\
\hline & \multicolumn{2}{|c|}{$\mathrm{HD}$} & \multicolumn{2}{|r|}{$\mathrm{PD}$} & \multicolumn{2}{|c|}{ Live transplant } & \multicolumn{2}{|c|}{ Deceased donor transplant } \\
\hline & $\mathrm{N}$ & $\%$ & $\mathrm{~N}$ & $\%$ & $\mathrm{~N}$ & $\%$ & $\mathrm{~N}$ & $\%$ \\
\hline $0-1.99$ years & 5 & 26.3 & 12 & 63.2 & 2 & 10.5 & 0 & 0.0 \\
\hline $2-3.99$ years & 10 & 21.7 & 17 & 37.0 & 15 & 32.6 & 4 & 8.7 \\
\hline $4-7.99$ years & 13 & 9.5 & 18 & 13.1 & 52 & 38.0 & 54 & 39.4 \\
\hline $8-11.99$ years & 10 & 5.7 & 14 & 8.0 & 64 & 36.4 & 88 & 50.0 \\
\hline $12-15.99$ years & 24 & 8.1 & 18 & 6.1 & 111 & 37.4 & 144 & 48.5 \\
\hline $16-17.99$ years & 19 & 10.5 & 11 & 6.1 & 57 & 31.5 & 94 & 51.9 \\
\hline Under 16 years & 62 & 9.2 & 79 & 11.7 & 244 & 36.1 & 290 & 43.0 \\
\hline Under 18 years & 81 & 9.4 & 90 & 10.5 & 301 & 35.2 & 384 & 44.9 \\
\hline
\end{tabular}


Table 4.5. Number, percentage and gender by primary renal disease as cause of ERF in the prevalent paediatric ERF population under 16 years in $2011^{*}$

\begin{tabular}{|c|c|c|c|c|c|}
\hline Diagnostic group & Total & $\%$ & Male & Female & $\mathrm{M}: \mathrm{F}$ ratio \\
\hline Obstructive uropathy & 121 & 17.9 & 114 & 7 & 16.3 \\
\hline Congenital nephrotic syndrome & 66 & 9.8 & 37 & 29 & 1.3 \\
\hline Tubulo-interstitial diseases & 52 & 7.7 & 23 & 29 & 0.8 \\
\hline Uncertain aetiology & 31 & 4.6 & 14 & 17 & 0.8 \\
\hline Metabolic & 22 & 3.3 & 11 & 11 & 1.0 \\
\hline Malignancy \& associated disease & 14 & 2.1 & 5 & 9 & 0.6 \\
\hline Missing & 3 & 0.4 & 1 & 2 & 0.5 \\
\hline Total & 675 & 100.0 & 408 & 267 & 1.53 \\
\hline
\end{tabular}

* this year there were no patients with ERF secondary to 'drug nephrotoxicity'

commonest, reported in $9.2 \%$, whilst both developmental delay and syndromic diagnoses each were reported in over $6 \%$ of patients. Prematurity was also frequently reported $(7.1 \%)$, whilst neural tube defects were least common in $0.3 \%$ of patients. Overall $68.9 \%$ of patients had no registered comorbidities, with $20.4 \%$ having one comorbidity listed, and $10.7 \%$ having two or more comorbidities. Centre analysis showed significant variation in reporting of registered co-morbidities, with some centres, Birmingham (88\%), Glasgow (83\%), GOSH $(80 \%)$ and Cardiff (80\%) reporting no comorbidity in the majority of their patients, as compared to other centres which reported no comorbidity in a smaller proportion of patients, Bristol (43\%) and Leeds (45\%).

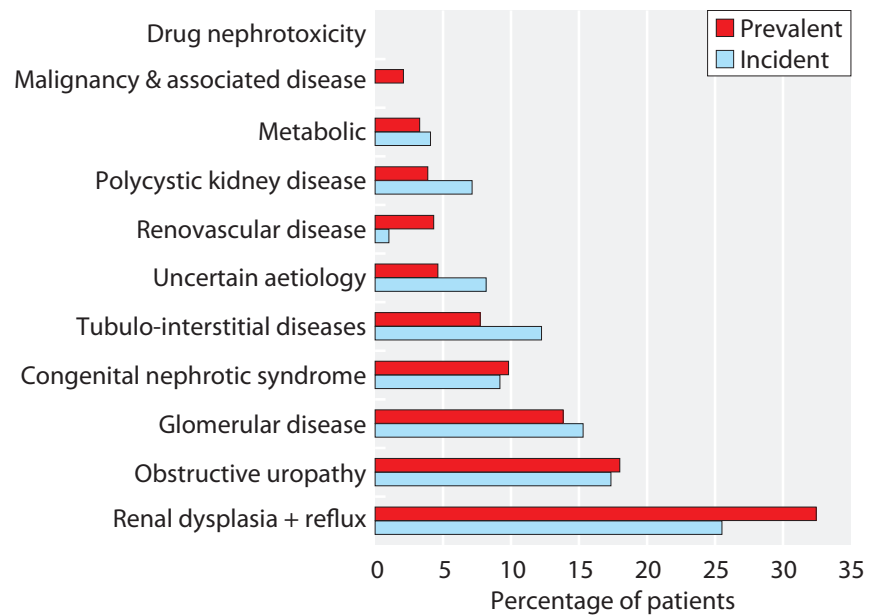

Fig. 4.3. Primary renal disease percentage in incident and prevalent paediatric ERF patients in 2011 for whom a causative diagnosis was reported
The UK incident paediatric ERF population in 2011

There were 114 patients under 18 years of age who commenced RRT at paediatric renal centres in 2011. As previously, the following analyses are restricted to the 99 patients who were under 16 years of age.

The incidence rate of RRT was 8.3 pmarp in 2011. Patients commencing RRT in 2011 are displayed by age and gender in table 4.7 .

Table 4.8 shows that the reported incidence of RRT has been rising since 1997, with the highest incidence rates seen in the 12-15.99 year age group, with the $0-1.99$ year age group having the next highest rates.

Table 4.6. Registered comorbidities at onset of RRT in prevalent paediatric patients aged $<16$ years with ERF in 2011

\begin{tabular}{lrc}
\hline Comorbidity & N & $\begin{array}{c}\text { Percentage all } \\
\text { RRT patients }\end{array}$ \\
\hline Cerebral palsy & 11 & 1.6 \\
Chromosomal abnormality & 18 & 2.7 \\
Congenital abnormality & 62 & 9.2 \\
Congenital heart disease & 12 & 1.8 \\
Consanguinity & 24 & 3.6 \\
Developmental delay & 46 & 6.8 \\
Diabetes & 2 & 0.3 \\
Family member with ERF & 19 & 2.8 \\
Liver disease & 12 & 1.8 \\
Malignancy & 7 & 1.0 \\
Neural tube defect & 2 & 0.3 \\
Prematurity & 48 & 7.1 \\
Psychological disorder & 8 & 1.2 \\
Syndromic diagnosis & 43 & 6.4 \\
No reported comorbidity & 465 & 68.9 \\
One reported comorbidity & 138 & 20.4 \\
Two or more comorbidities & 72 & 10.7 \\
\hline
\end{tabular}

Nephron Clin Pract 2013;123(suppl1):81-92 
Table 4.7. The incident paediatric ERF population in the UK in 2011, by age group and gender

\begin{tabular}{|c|c|c|c|c|c|c|c|}
\hline \multirow[b]{2}{*}{ Age group } & \multicolumn{2}{|c|}{ All patients } & \multicolumn{2}{|c|}{ Male } & \multicolumn{2}{|c|}{ Female } & \multirow[b]{2}{*}{$\mathrm{M}: \mathrm{F}$ ratio } \\
\hline & $\mathrm{N}$ & pmarp & $\mathrm{N}$ & pmarp & $\mathrm{N}$ & pmarp & \\
\hline $0-1.99$ years & 16 & 10.1 & 12 & 14.7 & 4 & 5.1 & 2.9 \\
\hline $2-3.99$ years & 10 & 6.3 & 9 & 11.2 & 1 & 1.3 & 8.6 \\
\hline $4-7.99$ years & 14 & 4.8 & 9 & 6.0 & 5 & 3.5 & 1.7 \\
\hline $8-11.99$ years & 25 & 9.0 & 12 & 8.5 & 13 & 9.6 & 0.9 \\
\hline $12-15.99$ years & 34 & 11.3 & 21 & 13.6 & 13 & 8.9 & 1.5 \\
\hline Under 16 years & 99 & 8.3 & 63 & 10.4 & 36 & 6.2 & 1.7 \\
\hline
\end{tabular}

pmarp - per million age related population

\section{Trends in ERF demographics}

There were 1,656 children under 16 years of age who had received RRT in the UK over the 15 -year period between 1997-2011. Analysis of ERF demographics for children less than 16 years of age over this period included 534 patients reported to the paediatric registry between 1997-2001, 527 between 2002-2006 and 595 between 2007-2011. Comparing the current 5 year period with the two previous 5 year periods there has been an overall increase in the number of children treated with RRT, particularly in children aged under 4 years

Table 4.8. Reported average incident rate by age group, in 5-year time periods, of children under 16 years of age commencing RRT

\begin{tabular}{lccc}
\hline & \multicolumn{3}{c}{ Per million age related population } \\
\cline { 2 - 4 } Age group & $1997-2001$ & $2002-2006$ & $2007-2011$ \\
\hline 0-1.99 years & 11.6 & 11.7 & 13.2 \\
2-3.99 years & 6.3 & 4.7 & 8.2 \\
4-7.99 years & 5.3 & 6.5 & 6.4 \\
8-11.99 years & 8.3 & 7.6 & 9.1 \\
12-15.99 years & 13.1 & 13.4 & 14.6 \\
Under 16 years & $\mathbf{8 . 9}$ & $\mathbf{9 . 1}$ & $\mathbf{1 0 . 3}$ \\
\hline
\end{tabular}

(table 4.9). The percentage of children on RRT who are from South Asian or Black ethnic backgrounds has also increased during this period (table 4.10). The reported patient population at most paediatric renal centres has similarly grown in size since 1997-2001 with Belfast showing the largest proportional rise (table 4.11).

Table 4.12 shows the number and percentage of children receiving RRT with each of the major reported comorbidities over the last 15 years. Whilst congenital abnormalities (6.9\%), developmental delay (6.2\%) and syndromic diagnoses $(6.4 \%)$ were the most common reported comorbidities in 2007-2011, there has been little change in the percentage of children receiving RRT with a reported comorbidity over the last 15 years.

As for changes in modality at the start of RRT, figure 4.4 shows that the percentage of children who were using PD at the start of RRT has fallen from $51.5 \%$ in $1997-2001$ to $44 \%$ in $2007-2011$ whilst the percentage commencing RRT on HD has increased from $22.8 \%$ in $1997-2001$ to $29.4 \%$ in $2007-2011$. During this period the overall percentage receiving a transplant at the start of RRT has remained largely unchanged though living donation has risen from $7.5 \%$ in $1997-2001$ to $16.4 \%$ in $2007-2011$, with a

Table 4.9. Number and percentage of children who commenced RRT, by age group and 5 year period, at start of RRT

\begin{tabular}{|c|c|c|c|c|c|c|c|}
\hline \multirow[b]{2}{*}{ Age group } & \multicolumn{2}{|c|}{$1997-2001$} & \multicolumn{2}{|c|}{ 2002-2006 } & \multicolumn{2}{|c|}{ 2007-2011 } & \multirow{2}{*}{$\begin{array}{l}1997-2011 \\
\% \text { change }\end{array}$} \\
\hline & $\mathrm{N}$ & $\%$ & $\mathrm{~N}$ & $\%$ & $\mathrm{~N}$ & $\%$ & \\
\hline $2-3.99$ years & 46 & 8.6 & 31 & 5.9 & 61 & 10.3 & 1.6 \\
\hline $4-7.99$ years & 80 & 15.0 & 92 & 17.5 & 89 & 15.0 & 0.0 \\
\hline $8-11.99$ years & 130 & 24.3 & 113 & 21.4 & 126 & 21.2 & -3.2 \\
\hline Under 16 years & 534 & & 527 & & 595 & & \\
\hline
\end{tabular}


Table 4.10. Number and percentage of children under 16 years who commenced RRT, by ethnicity and 5 year period of starting RRT

\begin{tabular}{|c|c|c|c|c|c|c|c|}
\hline \multirow[b]{2}{*}{ Ethnic group } & \multicolumn{2}{|c|}{ 1997-2001 } & \multicolumn{2}{|c|}{ 2002-2006 } & \multicolumn{2}{|c|}{ 2007-2011 } & \multirow{2}{*}{$\begin{array}{l}\text { 1997-2011 } \\
\% \text { change }\end{array}$} \\
\hline & $\mathrm{N}$ & $\%$ & $\mathrm{~N}$ & $\%$ & $\mathrm{~N}$ & $\%$ & \\
\hline South Asian & 78 & 14.8 & 80 & 15.4 & 88 & 15.1 & 0.3 \\
\hline Black & 14 & 2.7 & 13 & 2.5 & 24 & 4.1 & 1.5 \\
\hline Other & 22 & 4.2 & 18 & 3.5 & 36 & 6.2 & 2.0 \\
\hline
\end{tabular}

${ }^{\star}$ There were 7 children in 1997-2001, 9 in 2002-2006 and 11 in 2007-2011 with no ethnicity recorded and these are excluded from this table

Table 4.11. Number and percentage of children under 16 years reported to the UKRR, by renal centre and 5 year period of starting RRT

\begin{tabular}{|c|c|c|c|c|c|c|c|}
\hline \multirow[b]{2}{*}{ Centre } & \multicolumn{2}{|c|}{ 1997-2001 } & \multicolumn{2}{|c|}{ 2002-2006 } & \multicolumn{2}{|c|}{ 2007-2011 } & \multirow{2}{*}{$\begin{array}{l}\text { 1997-2011 } \\
\% \text { change }\end{array}$} \\
\hline & $\mathrm{N}$ & $\%$ & $\mathrm{~N}$ & $\%$ & $\mathrm{~N}$ & $\%$ & \\
\hline Blfst_P & 15 & 2.8 & 15 & 2.9 & 27 & 4.5 & 1.7 \\
\hline Bham_P & 50 & 9.4 & 54 & 10.3 & 62 & 10.4 & 1.0 \\
\hline Brstl_ $\bar{P}$ & 38 & 7.2 & 37 & 7.0 & 35 & 5.9 & -1.3 \\
\hline Cardf_P & 14 & 2.6 & 19 & 3.6 & 16 & 2.7 & 0.1 \\
\hline Glasg_P & 42 & 7.9 & 29 & 5.5 & 46 & 7.7 & -0.2 \\
\hline L Eve_P & 55 & 10.4 & 45 & 8.6 & 68 & 11.4 & 1.1 \\
\hline L GOS̄H_P & 94 & 17.7 & 101 & 19.2 & 114 & 19.2 & 1.5 \\
\hline Leeds_P & 44 & 8.3 & 52 & 9.9 & 47 & 7.9 & -0.4 \\
\hline Livpl_P & 21 & 4.0 & 31 & 5.9 & 19 & 3.2 & -0.8 \\
\hline Manch_P & 52 & 9.8 & 51 & 9.7 & 50 & 8.4 & -1.4 \\
\hline Newc_P & 29 & 5.5 & 27 & 5.1 & 27 & 4.5 & -0.9 \\
\hline Nottm_P & 59 & 11.1 & 46 & 8.7 & 64 & 10.8 & -0.4 \\
\hline Soton_P & 18 & 3.4 & 19 & 3.6 & 20 & 3.4 & 0.0 \\
\hline Total $<16$ & 531 & & 526 & & 595 & & \\
\hline
\end{tabular}

*there were 3 children in 1997-2001 and 1 in 2002-2006 with unknown centre of RRT start and these are excluded from this table

Table 4.12. Trends in comorbidity at the start of RRT in the paediatric population under 16 years, by 5 year period

\begin{tabular}{|c|c|c|c|c|c|c|c|}
\hline \multirow[b]{2}{*}{ Comorbidity } & \multicolumn{2}{|c|}{ 1997-2001 } & \multicolumn{2}{|c|}{ 2002-2006 } & \multicolumn{2}{|c|}{$2007-2011$} & \multirow{2}{*}{$\begin{array}{l}\text { 1997-2011 } \\
\% \text { change }\end{array}$} \\
\hline & $\mathrm{N}$ & $\%$ & $\mathrm{~N}$ & $\%$ & $\mathrm{~N}$ & $\%$ & \\
\hline Chromosomal abnormality & 18 & 3.4 & 8 & 1.5 & 17 & 2.9 & -0.5 \\
\hline Congenital abnormality & 36 & 6.7 & 54 & 10.2 & 41 & 6.9 & 0.1 \\
\hline Congenital heart disease & 15 & 2.8 & 7 & 1.3 & 17 & 2.9 & 0.0 \\
\hline Diabetes & 3 & 0.6 & 5 & 0.9 & 2 & 0.3 & -0.2 \\
\hline Family member with ERF & 26 & 4.9 & 18 & 3.4 & 10 & 1.7 & -3.2 \\
\hline Liver disease & 0 & 0.0 & 9 & 1.7 & 13 & 2.2 & 2.2 \\
\hline Malignancy & 8 & 1.5 & 7 & 1.3 & 2 & 0.3 & -1.2 \\
\hline Neural tube defect & 3 & 0.6 & 4 & 0.8 & 2 & 0.3 & -0.2 \\
\hline Prematurity & 35 & 6.6 & 23 & 4.4 & 29 & 4.9 & -1.7 \\
\hline One reported comorbidity & 109 & 20.4 & 133 & 25.2 & 99 & 16.6 & -3.8 \\
\hline Two or more comorbidities & 62 & 11.6 & 53 & 10.1 & 56 & 9.4 & -2.2 \\
\hline
\end{tabular}




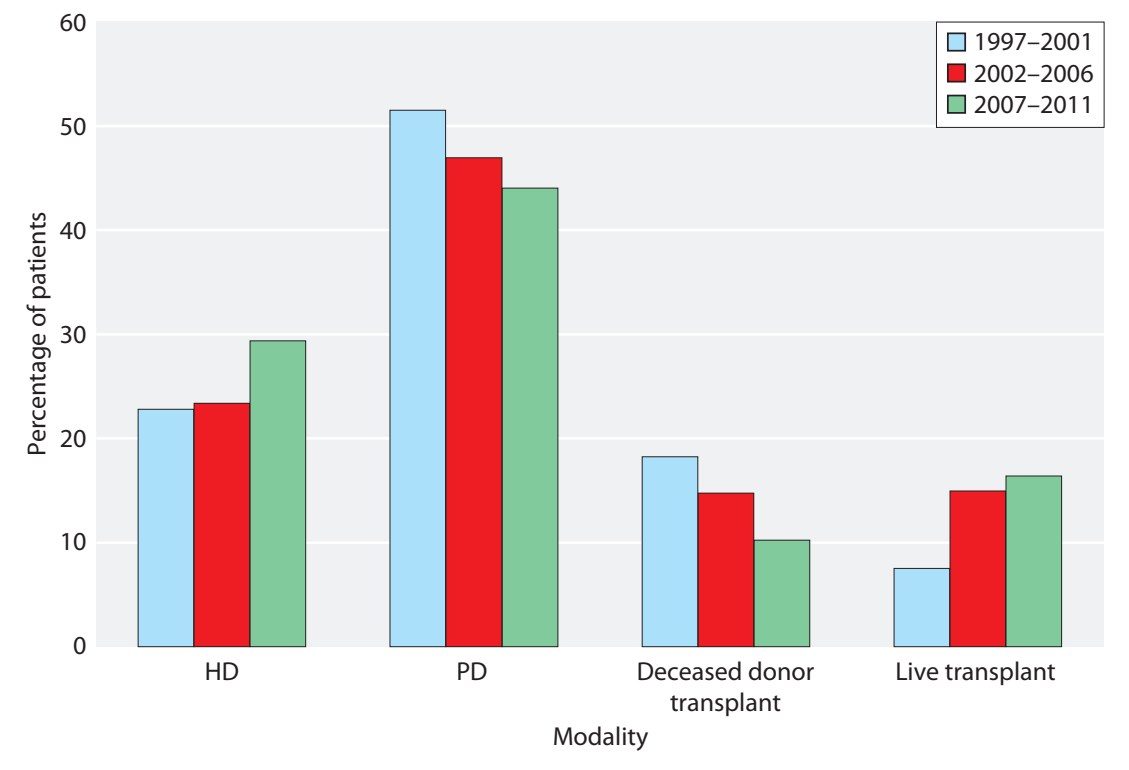

Fig. 4.4. Treatment modality at start of RRT by 5 year time period corresponding fall in deceased donor transplantation from $18.2 \%$ to $10.2 \%$ for the same time period.

Table 4.13 shows the diagnostic categories for 523 of the $534(97.9 \%)$ patients in 1997-2001, for 512 of the $528(97 \%)$ patients in 2002-2006 and 582 of the 596 $(97.7 \%)$ patients in $2007-2011$ aged $<16$ years for whom a causative diagnosis was reported.

Overall there has been an increase in the percentage of children receiving RRT with unknown aetiology between 1997-2001 and 2007-2011 (1.3\% vs. 6.0\%) and a decrease in glomerular disease $(22.2 \%$ vs. $20.1 \%)$ though absolute numbers are very small (table 4.13 ).

\section{Pre-emptive transplantation}

Of a total of 1,656 patients who started RRT between 1997-2011, 448 patients were excluded from analysis (93 patients were excluded due to being aged $<3$ months, and a further 355 patients were excluded due to being 'late presenters'). Of 1,208 patients identified as being aged 3 months to $<16$ years and having started RRT between 1997-2011, pre-emptive transplantation was seen to occur in $30.6 \%$ of patients and was significantly higher in males (33.6\%) than females (25.8\%), $\mathrm{p}=0.004$ (table 4.14). Ethnicity was also seen to be a significant factor, with children from Black (12.1\%)

Table 4.13. Number and percentage of children under 16 years for whom a primary renal diagnosis had been reported as a cause of ERF, by 5 year time period and observed change in proportion of patients in each diagnostic group ${ }^{*}$

\begin{tabular}{|c|c|c|c|c|c|c|c|}
\hline \multirow[b]{2}{*}{ Primary renal diagnosis } & \multicolumn{2}{|c|}{$1997-2001$} & \multicolumn{2}{|c|}{ 2002-2006 } & \multicolumn{2}{|c|}{ 2007-2011 } & \multirow{2}{*}{$\begin{array}{l}\text { 1997-2011 } \\
\% \text { change }\end{array}$} \\
\hline & $\mathrm{N}$ & $\%$ & $\mathrm{~N}$ & $\%$ & $\mathrm{~N}$ & $\%$ & \\
\hline Renal dysplasia \pm reflux & 163 & 31.2 & 175 & 34.2 & 173 & 29.7 & -1.4 \\
\hline Obstructive uropathy & 81 & 15.5 & 78 & 15.2 & 93 & 16.0 & 0.5 \\
\hline Glomerular disease & 116 & 22.2 & 101 & 19.7 & 117 & 20.1 & -2.1 \\
\hline Congenital nephrotic syndrome & 33 & 6.3 & 23 & 4.5 & 38 & 6.5 & 0.2 \\
\hline Tubulo-interstitial diseases & 41 & 7.8 & 42 & 8.2 & 46 & 7.9 & 0.1 \\
\hline Uncertain aetiology & 7 & 1.3 & 28 & 5.5 & 35 & 6.0 & 4.7 \\
\hline Renovascular disease & 22 & 4.2 & 15 & 2.9 & 20 & 3.4 & -0.8 \\
\hline Polycystic kidney disease & 14 & 2.7 & 15 & 2.9 & 21 & 3.6 & 0.9 \\
\hline Metabolic & 30 & 5.7 & 19 & 3.7 & 29 & 5.0 & -0.8 \\
\hline Malignancy \& associated disease & 4 & 0.8 & 10 & 2.0 & 8 & 1.4 & 0.6 \\
\hline Drug nephrotoxicity & 12 & 2.3 & 6 & 1.2 & 2 & 0.3 & -2.0 \\
\hline
\end{tabular}

* there were 11 children in 1997-2001, 16 in 2002-2006 and 14 in 2007-2011 with no PRD recorded and these are excluded from this table 
Table 4.14. Demographics of pre-emptive transplantation in children aged 3 months to 16 years in the UK between 19972011, analysed by 5 year time period, gender, ethnicity, age at start of RRT and primary renal diagnosis

\begin{tabular}{|c|c|c|}
\hline & $\mathrm{N}$ & $\begin{array}{c}\mathrm{N}(\%) \\
\text { pre-emptively } \\
\text { transplanted }\end{array}$ \\
\hline Total cohort analysed (1997-2011) & 1,208 & $370(30.6)$ \\
\hline $\begin{array}{l}\text { Time Period } \\
1997-2001 \\
2002-2006 \\
2007-2011\end{array}$ & $\begin{array}{l}389 \\
400 \\
419\end{array}$ & $\begin{array}{l}101(26.0) \\
131(32.8) \\
138(32.9)\end{array}$ \\
\hline $\begin{array}{l}\text { Gender } \\
\text { Male } \\
\text { Female }\end{array}$ & $\begin{array}{l}750 \\
458\end{array}$ & $\begin{array}{l}252(33.6) \\
118(25.8)\end{array}$ \\
\hline $\begin{array}{l}\text { Ethnicity } \\
\text { Black } \\
\text { Other } \\
\text { South Asian } \\
\text { White }\end{array}$ & $\begin{array}{r}33 \\
49 \\
189 \\
912\end{array}$ & $\begin{array}{r}4(12.1) \\
13(26.5) \\
34(18.0) \\
306(33.6)\end{array}$ \\
\hline $\begin{array}{l}\text { Age at start of RRT } \\
3 \text { months }-1.99 \text { years } \\
2-3.99 \text { years } \\
4-7.99 \text { years } \\
8-12.99 \text { years } \\
12-15.99 \text { years }\end{array}$ & $\begin{array}{l}118 \\
113 \\
211 \\
287 \\
479\end{array}$ & $\begin{aligned} & 8(6.8) \\
& 27(23.9) \\
& 71(33.7) \\
& 96(33.5) \\
& 168(35.1)\end{aligned}$ \\
\hline $\begin{array}{l}\text { Primary Renal Diagnosis } \\
\text { Renal dysplasia } \pm \text { reflux } \\
\text { Glomerular disease } \\
\text { Obstructive uropathy } \\
\text { Tubulo-interstitial diseases } \\
\text { Congenital nephrotic syndrome } \\
\text { Metabolic } \\
\text { Polycystic kidney disease } \\
\text { Renovascular disease } \\
\text { Uncertain aetiology } \\
\text { Malignancy \& associated disease } \\
\text { Drug nephrotoxicity }\end{array}$ & $\begin{array}{r}379 \\
231 \\
220 \\
78 \\
77 \\
66 \\
39 \\
32 \\
31 \\
13 \\
12 \\
\end{array}$ & $\begin{aligned} & 154(40.6) \\
& 27(11.7) \\
& 95(43.2) \\
& 16(20.5) \\
& 4(5.2) \\
& 23(34.9) \\
& 16(41.0) \\
& 11(34.4) \\
& 7(22.6) \\
& 2(15.4) \\
& 3(25.0) \\
&\end{aligned}$ \\
\hline
\end{tabular}

and South Asian (18\%) ethnicity having significantly lower rates of transplantation than their White counterparts (33.6\%), p $<0.0001$. Analysis by age at start of RRT showed that as expected, the lowest rate of pre-emptive transplantation was in the 3 months to 2 year group $(6.8 \%)$, whilst children aged 4 to 16 years had similar rates of pre-emptive transplantation. As for PRD, children with obstructive uropathy $(43.2 \%)$, polycystic kidney disease $(41 \%)$ and renal dysplasia \pm reflux $(40.6 \%)$ had the highest rates of pre-emptive transplantation, whilst those with congenital nephrotic syndrome $(5.2 \%)$ and glomerular disease $(11.7 \%)$ had the lowest rates. Over time there appears to have been a rise in
Table 4.15. Modality, gender, ethnicity and primary renal diagnosis of patients transferred out of paediatric nephrology centres in 2011

\begin{tabular}{lrc}
\hline & & $\begin{array}{c}\% \\
\text { distribution }\end{array}$ \\
\hline Modality & & \\
HD & 8 & 8.6 \\
PD & 5 & 5.4 \\
Transplant & 80 & 86.0 \\
Gender & & \\
Female & 32 & 65.6 \\
Male & 61 & 34.4 \\
Ethnicity & & \\
Black & 0 & 0.0 \\
Other & 2 & 2.2 \\
South Asian & 8 & 8.9 \\
White & 80 & 88.9 \\
Primary renal diagnosis* & & \\
Renal dysplasia \pm reflux & 33 & 36.3 \\
Glomerular disease & 22 & 24.2 \\
Obstructive uropathy & 11 & 12.1 \\
Tubulo-interstitial diseases & 7 & 7.7 \\
Metabolic & 6 & 6.6 \\
Polycystic kidney disease & 3 & 3.3 \\
Renovascular disease & 3 & 3.3 \\
Congenital nephrotic syndrome & 2 & 2.2 \\
Uncertain aetiology & 2 & 2.2 \\
Drug nephrotoxicity & 1 & 1.1 \\
Malignancy \& associated disease & 1 & 1.1 \\
\hline *eity ming $~$
\end{tabular}

*ethnicity missing in 1 patient, and PRD missing in 3 patients

pre-emptive transplantation rates, rising from $26 \%$ in $1997-2001$ to $32.9 \%$ in $2007-2011, \mathrm{p}=0.05$ (table 4.14 ).

Transfer of patients to adult renal services in 2011

A total of 93 patients were reported by paediatric nephrology centres to have been transferred to adult renal services in 2011. The median age of patients transferred out was 18.0 years with an inter-quartile range of 17.5 years to 18.8 years. Manchester, Leeds and Bristol had the largest numbers of adolescents transferred to adult services in 2011.

Table 4.15 shows that of the transferred patients $65.6 \%$ were male, with ethnic minorities constituting $11.1 \%$ of patients. The vast majority $(86 \%)$ had a functioning renal transplant at the time of transfer to an adult renal centre. Renal dysplasia \pm reflux was the primary renal diagnosis in over a third of patients.

\section{Survival of children on RRT during childhood}

Of patients under the age of $16,1,551$ were identified as starting RRT between 1997 and 2010 at paediatric 
Table 4.16. Survival hazard ratio during childhood for paediatric RRT patients age $<16$ years in the UK adjusted for age at start of RRT, gender and RRT modality

\begin{tabular}{lccc}
\hline & $\begin{array}{c}\text { Hazard } \\
\text { ratio }\end{array}$ & $\begin{array}{c}\text { Confidence } \\
\text { interval }\end{array}$ & p-value \\
\hline Age & & & \\
0-1.99 years & 5.13 & $2.62-10.03$ & $<0.0001$ \\
2-3.99 years & 2.69 & $1.20-6.02$ & 0.02 \\
4-7.99 years & 1.48 & $0.65-3.34$ & 0.35 \\
8-11.99 years & 1.19 & $0.52-2.71$ & 0.68 \\
12-16 years & 1.00 & - & - \\
Gender & & & 0.19 \\
Female & 1.31 & $0.88-1.94$ & - \\
Male & 1.00 & - & $<0.0001$ \\
RRT modality & & & - \\
Dialysis & 6.04 & $3.28-11.15$ & \\
Transplant & 1.00 & - & \\
\hline
\end{tabular}

centres in the UK and were included in the survival analyses. At the census date (31st December 2011) there were a total of 104 deaths within the cohort on RRT at age $<16$, with a median follow up time of 3.4 years (range of 1 day to 15 years). Table 4.16 shows the survival hazard ratios after adjustment for age at start of RRT, gender and RRT modality, and highlights that children starting RRT at 0-1.99 years have the worst survival outcomes with a hazard ratio of 5.13 (CI $2.62-10.03, \mathrm{p}<0.0001)$ when compared to $12-16$ years olds. Outcomes in the 2-3.99 age group were also significantly lower with a hazard ratio of 2.69 (CI 1.2-6.02, $p=0.02$ ). Gender was not seen to have any impact on survival although being on dialysis as expected was seen to lower survival significantly compared to having a functioning transplant with a hazard ratio of 6.04 $(3.28-11.15, \mathrm{p}<0.0001)$. Figure 4.5 shows unadjusted Kaplan Meier survival probabilities. As the maximum age of follow up was restricted to 16 years, it was not possible to calculate 10 year survival probabilities for patients starting RRT aged $>8$ years, or 5 year survival probability for children starting RRT aged $>12$ years. This figure again highlights worse outcomes for those aged $0-1.99$ years.

\section{Mortality data in 2011}

There were nine deaths in renal paediatric centres in 2011. The reported mortality of children with treated ERF in 2011 in the UK at paediatric centres was 1.3\% (9/675). The median age at death was 7.8 years with a range of 1.7 years to 16.9 years. Sepsis was cited as a cause of death in four patients, two of which were associated with peritonitis and one due to bowel

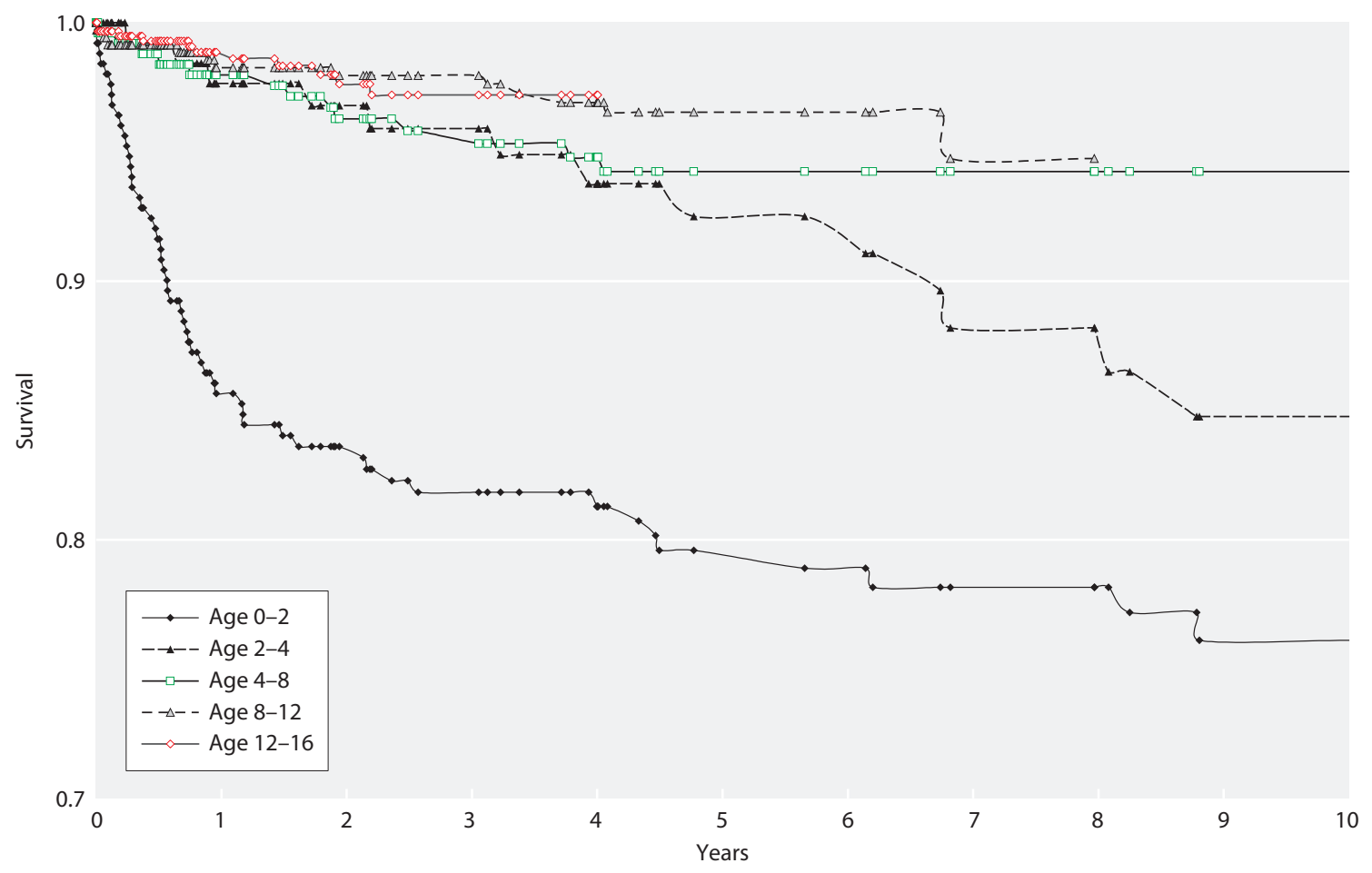

Fig. 4.5. Unadjusted KM in paediatric patients starting RRT between 1997 and 2010 , by age at start 
obstruction. Haemorrhage (gastrointestinal bleed and an intra-cerebral haemorrhage) was the cause of death in a further two patients. A clear cause of death could not be identified in the three remaining patients who died in 2011.

\section{Discussion}

This report from the Paediatric Renal Registry has focussed on the current demography and the demographic trends over the past 15 years of the UK paediatric ERF population.

This report includes 675 children and adolescents under 16 years of age, who were receiving RRT in 2011. The sub-section on the trends in demographics includes children and adolescents under 16 years of age on RRT; 534 from 1997-2001, 527 from 2002-2006 and 595 from 2007-2011.

\section{Data completeness}

The ongoing sustained effort to improve data accuracy must continue and the aim to move to full electronic annual returns from all centres remains. A revised data set (The NEW Paediatric Dataset) will be used for future registry returns. These ongoing efforts to improve the quality and consistency of the data received will be rewarded by enabling enhanced interpretation of centre specific measures of clinical performance.

\section{Incidence, prevalence and trends}

The incidence rate of RRT in the less than 16 year age group was 8.3 pmarp in 2011; this rate has been rising since 1997. The overall prevalence rate of RRT in the less than 16 year age group was 56.8 pmarp. The prevalence of RRT increased with age and was higher in males across all age groups. The number of children receiving RRT also continued to rise particularly in the under 2-year age group. Overall, there was a continuing trend of increased prevalence of children on RRT with increased age, in keeping with improved survival with increasing age. This coupled with an increase in the number of children receiving RRT over the past 15 years has led to a steady increase in the prevalent ERF population.

\section{Treatment modality of ERF and observed trends}

1997-2011

Peritoneal dialysis was the initial treatment modality for $48 \%$ of children at the start of treatment, $28 \%$ commenced HD and $24 \%$ received a pre-emptive transplant. Age influenced the modality of RRT with the majority of the under 2's (63\%) receiving PD. Overall the majority of prevalent children (79\%) on RRT had a functioning transplant.

\section{Pre-emptive transplantation}

Pre-emptive transplantation was seen to occur in 30\% of children under 16 years age. The rate of pre-emptive transplantation has increased over the past 15 years $(26.0 \%$ in $1997-2001$ to $33 \%$ in $2007-2011)$. There were significantly lower rates of pre-emptive transplantation in girls and ethnic minorities and further detailed studies investigating these would be important.

\section{Comorbidities}

At the onset of RRT, $31 \%$ of patients had 1 or more associated comorbidity. This overall percentage has remained similar over the past 15 years. Of note is the significant variation in registered comorbidity rate between centres ( $43 \%$ to $88 \%$, data not shown); it is likely that this is influenced by different reporting practices between centres. It is hoped that the recently agreed NEW Paediatric Dataset will help improve consistency and reliability of data submission thus improving report accuracy.

\section{Causes of ERF and observed trends 1997-2011}

As previously, renal dysplasia \pm reflux (30\%), glomerular disease (20\%) and obstructive uropathy (16\%) were the commonest listed aetiologies for children with ERF. These accounted for $66 \%$ of all patients for whom a primary diagnosis had been reported. Observation of trends over the 15-year period showed an increase in the percentage of children receiving RRT with unknown aetiology.

\section{Transfer out and survival data}

Data relating to transfer to adult renal services is included in the current report. The median age of transfer was 18.0 years. Of patients receiving RRT, 86\% transferred with a functioning renal transplant. There appears to be variation in practice between centres regarding transition and transfer out arrangements; it is also likely that variability exists in reporting of 'transfer out' timelines to the registry for patients being transitioned to adult centres. Consensus regarding terminology will facilitate future comparative interpretation.

Survival data of children on ERF during childhood who commenced RRT between 1997 and 2010 highlights 
the less favourable outcome for children less than 2 years of age. Longer term survival data up to 5 years was available for those $<12$ years and 10 year survival data for those $<8$ years only. For the majority of children on RRT long term survival data will need follow up in to young adulthood. This is the focus of an ongoing project of the UK Renal Registry.

Conflicts of interest: none

\section{References}

1 Pruthi R, Sinha MD, Casula A, Tse Y, Maxwell H, O'Brien C, Lewis M, Inward C. UK Renal Registry 14th Annual Report (December 2010): Chapter 5 Demography of the UK Paediatric Renal Replacement Therapy Population in 2010. Nephron Clin Prac 2012; 120(suppl 1):c93-c103; DOI: $10.1159 / 000342847$

2 http://www.Ons.Gov.Uk/census 